Disclosure of interest statement ACON acknowledges its primary funder, the NSW Ministry of Health. ACON has not received pharmaceutical grants for this work.

\section{P14.08 COMPARATIVE STUDY OF VULNERABILITY OF CIRCUMCISION AMONG WOMEN OF KENYA AND NIGERIA}

Ankita Siddhanta*. International Institute for Population Sciences, India

10.1136/sextrans-2015-052270.520

Introduction Female circumcision is a phenomenon specific to Africa continent. The main objective of study is to understand the determinant affecting female circumcision in the two selected African countries of Kenya and Nigeria.

Methods Bivariate and Multivariate techniques were used to analyse DHS Data for this study.

Results Most Kenyan women (90\%) are of the view that circumcision should be discontinued compared to $74 \%$ in Nigeria. In both the countries, with increasing age and education the attitude and perception of the women towards the continuation of the service is getting negative $(\mathrm{P}<0.01)$. It is found that high percentage $(86.6 \%)$ of women from Christian community in Kenya as compared to only $66 \%$ in Nigeria believe that this tradition has no benefit. In Kenya, circumcision among Islam women $(55 \%)$ doubles than the Christians whereas in Nigeria, this practice among the Christians is equally high (47.3\%). The Islam women in Kenya are 2.7 times more likely than the Christians to say that this practice should be continued and 35\% want her daughter to be circumcised compared to only $5.7 \%$ in Nigeria. Surprisingly, $17 \%$ women in Kenya and $25 \%$ in Nigeria experienced circumcision even after marriage thus flouting the popular belief, that infibulated genitalia before marriage is much preferred option. Circumcised women are 11 times and 21 times more likely in Kenya and Nigeria respectively than uncircumcised women to want the persistence of circumcision.

Conclusion Aforesaid results clearly points out that the Nigerian women faces more circumcision and are exposed conformed to socially constructed norms. The findings reiterated the basic nature of human where we find that the women who went through the pain want other women also to be prisoners of circumcised pain. Expansion of reproductive health policies, planning and programming should include Circumcision to address the vulnerabilities.

Disclosure of interest statement Not applicable.

\section{P14.09 ADVANCING HIV AND STI JUSTICE: THE KEY ROLE OF SCIENCE AND SCIENTISTS IN ENDING OVERLY BROAD HIV AND STI CRIMINALISATION}

EJ Bernard*. HIV Justice Network, UK

\subsection{6/sextrans-2015-052270.52}

Introduction Overly broad laws criminalising HIV and/or STI non-disclosure, exposure and/or non-intentional transmission exist in countries across the globe. Although some laws are HIVspecific, many prosecutions take place under general criminal or public health laws which allow for STI-related prosecutions. Although most attention has focused on HIV-related prosecutions, a growing number of prosecutions and new or proposed laws also relate to other STIs.
Methods A desk review of criminal proceedings, policy documents and newspaper reports related to HIV and STI-related laws and prosecutions in 2014-15.

Results Most reported HIV-related prosecutions continue to take place in North America, but are also being reported in every region of the world. Whilst international and local advocacy has delivered significant challenges to inappropriate and overly broad HIV-specific laws in a number of jurisdictions, and the science of HIV risk, harm and proof has had a significant impact on law and policy in some North American and Western European jurisdictions, new overly broad HIV-specific or STI-related laws continue to be proposed or enacted. Many HIV-related laws and prosecutions continue to inappropriately focus on spitting or non-disclosure even when no transmission is alleged, whilst others ignore the HIV prevention effect of condoms and/ or antiretroviral therapy. In addition, laws and prosecutions for other STIs, including for gonorrhoea, herpes, and syphilis, as well as sexually transmitted hepatitis B and C, and potentially even Ebola, are increasing.

Conclusion Criminal justice actors and law- and policymakers struggle with the science around HIV and STI risks, harm and proof, and are unaware of the unintended deleterious impacts of such laws and prosecutions. Scientists and clinicians have a key role to play to influence individual cases and broader laws and policies relating to prosecutions for HIV and STIs non-disclosure, exposure and/or transmission in order to improve both public health and human rights.

Disclosure of interest statement The HIV Justice Network is funded by Monument Trust, UK. No pharmaceutical grants were received in the development of this study.

\section{P14.10 FIGHT FOR THE RIGHT TO HEALTH CARE SERVICES FOR PEOPLE WITH HIV}

Dion Nuryadi*

\subsection{6/sextrans-2015-052270.522}

Background By September 2013, 70\% of districts/cities in Indonesia reported 45,650 HIV cases. The discrepancy between the estimated 500,000 HIV people and reported cases shows there is a great number of hidden PLHIV not reached by empowerment programs thus causing them experiencing low life-quality.

Description In 2012-2013, we strengthened organising PLHIV agreed to establish JAPI (Indonesian Action Network for Change), becoming a political agent of change; programs include: facilitating and publishing homebased-care module, together with $\mathrm{MoH}$ and IPPA, supervision and M\&E provincialvisits, expanding the network to include women, MSM, Transgender, IDUs human rights, environmental and global justice activists. In 2013-2014 JAPI's advocacy through series of workshop, executive consultations and campaign to fight for rights to health services for PLHIV in Indonesia. JAPI has published two training modules: (1) Psychosocial support for PLHIV (2) Community organising. JAPI also grew stronger becoming Evaluator for Access to health Team-members with $\mathrm{MoH}$ and national facilitator for Social analysis and positive prevention. There are 82 groups (GF/Implementing Units) in 12(of 33) provinces with 110 PLHIV -peer-facilitators supporting 39,056 PLHIV.

Lessons learned Through intensive PLHIV Community-Organising and training, PLHIV groups evolved from being objects of projects, turn into subjects in the AIDS response. 